\title{
Comparison of health-related quality of life in rheumatoid arthritis, psoriatic arthritis and psoriasis and effects of etanercept treatment
}

\author{
Vibeke Strand, ${ }^{1}$ Veronika Sharp, ${ }^{2}$ Andrew S Koenig, ${ }^{3}$ Grace Park, ${ }^{4}$ Yifei Shi, ${ }^{4}$ \\ Brian Wang, ${ }^{5}$ Debra J Zack, ${ }^{6}$ David Fiorentino ${ }^{7}$
}

\begin{abstract}
- An additional supplementary figure is published online only. To view this file please visit the journal online (http://ard.bmj.com/ content/71/7.toc).

1 Division of Immunology and Rheumatology, Stanford University, Palo Alto, California, USA

2Division of Rheumatology, Department of Medicine, Santa Clara Valley Medical Center, San Jose, California, USA ${ }^{3}$ Inflammation and Immunology, Pfizer Inc, Collegeville, Pennsylvania, USA ${ }^{4}$ Global Biostatistical Science, Amgen Inc, Thousand Oaks, California, USA

${ }^{5}$ Department of Biostatistics, KForce Clinical Research, Tampa, Florida, USA ${ }^{6}$ General Medicine and Inflammation Therapeutic Area, Amgen Inc, Thousand Oaks,

California, USA

${ }^{7}$ Department of Dermatology,

Stanford University, Palo Alto,

California, USA
\end{abstract}

\section{Correspondence to}

Vibeke Strand, Division of Immunology/Rheumatology, Stanford University, 306

Ramona Road, Portola Valley, CA 94028, USA

vstrand@stanford.edu

Received 30 June 2011 Accepted 7 December 2011 Published Online First 17 January 2012

\begin{abstract}
Objectives To compare health-related quality of life (HROoL) before and after treatment with etanercept in patients with moderate to severe rheumatoid arthritis (RA), psoriatic arthritis (PsA) and psoriasis using spydergram representations.
\end{abstract}

Methods Data from randomised, controlled trials of etanercept in patients with RA, PsA and psoriasis were analysed. HROoL was assessed by the medical outcomes survey short form 36 (SF-36) physical (PCS) and mental (MCS) component summary and domain scores. Baseline comparisons with age and gender-matched norms and treatment-associated changes in domain scores were quantified using spydergrams and the health utility SF-6D measure.

Results Mean baseline PCS scores were lower than age and gender-matched norms in patients with RA and PsA, but near normative values in patients with psoriasis; MCS scores at baseline were near normal in PsA and psoriasis but low in RA. Treatment with etanercept resulted in improvements in PCS and MCS scores as well as individual SF-36 domains across all indications. Mean baseline SF-6D scores were higher in psoriasis than in RA or PsA; clinically meaningful improvements in SF-6D were observed in all three patient populations following treatment with etanercept.

Conclusions Patients with RA, PsA and psoriasis demonstrated unique $\mathrm{HROOL}$ profiles at baseline. Treatment with etanercept was associated with improvements in PCS and MCS scores as well as individual domain scores in patients with RA, PsA and psoriasis.

Health-related quality of life (HRQoL) has been shown to be profoundly impaired in patients with bone and joint diseases, including rheumatoid arthritis (RA) ${ }^{1}$ and psoriatic arthritis (PsA). ${ }^{2-5}$ HRQoL is also impaired in psoriasis but to a different degree, as reflected by changes in the dermatology life quality index and the Euro-QoL. ${ }^{6-12}$ A prominent benefit of treatment with tumour necrosis factor (TNF) antagonists in patients with these diseases has been an improvement in patientreported outcomes, including HRQoL. ${ }^{1}{ }^{12-22}$

The medical outcomes survey short form 36 (SF-36) is a generic patient-reported measure of HRQoL that has been validated for use in most rheumatic diseases, including $\mathrm{RA}^{123}$ and $\mathrm{PsA}^{24} 25$ as well as psoriasis. ${ }^{26} 27$ It includes 36 questions combined into eight domains, which are summarised into physical component (PCS) and mental component (MCS) summary scores. ${ }^{1}$ SF-6D is a health utility score based on mean scores across all eight domains of the SF-36, which has been demonstrated to be sensitive to change in rheumatic diseases. ${ }^{1}$ 28-30 Importantly, SF-6D facilitates comparisons of baseline values and post-treatment changes in HRQoL.

The presentation and interpretation of HRQoL data from SF-36 is complex, and the impact of patterns of disease and treatment-associated effects can be difficult to evaluate. 'Spydergrams' provide an intuitive visual method to examine multiple domains of HRQoL simultaneously in a single figure. ${ }^{30}$ The objectives of this study were to use spydergrams to compare the impact on HRQoL of three different immune-mediated diseases, specifically in terms of how each disease differentially affects aspects of mental and physical wellbeing, and to use spydergrams to determine how etanercept therapy impacts changes in domains of the SF-36 across these diseases.

\section{Methods}

Data for these analyses were obtained from randomised controlled trials that have been published previously on patients with early RA (combination of methotrexate and etanercept in early RA; COMET), ${ }^{31-33}$ PsA (Study 160030) ${ }^{34}$ and psoriasis (Study 160042). ${ }^{17}$ Patients in COMET with early moderate to severe RA for a mean of 9 months were randomly assigned to receive etanercept (50 mg a week) in combination with methotrexate or methotrexate alone for 52 weeks. ${ }^{31}$ Patients with PsA for a mean of approximately 9 years were randomly assigned to receive etanercept (25 mg twice a week) or placebo for 24 weeks in Study 160030.34 Patients with active, clinically stable plaque psoriasis for a mean of 20.5 years in Study 160042 were randomly assigned to treatment with etanercept 25 mg twice a week or $50 \mathrm{mg}$ twice a week or placebo for 12 weeks (randomised controlled trial portion of the trial). ${ }^{17}$ Patients in all arms of the psoriasis study received etanercept $25 \mathrm{mg}$ twice a week open label for weeks 13-24.

In all studies, patients completed SF-36 questionnaires at baseline (before treatment) and at various protocol-specified times during treatment. The eight domains of SF-36 (see supplementary figure S1, 
available online only) include: limitations in physical activities because of health problems (physical function (PF)); limitations in usual role activities because of physical health problems (role physical (RP)); bodily pain (BP); general health perceptions $(\mathrm{GH})$; vitality (VT); limitations in social activities because of physical or emotional problems (social functioning (SF)); limitations in usual role activities because of emotional problems (role emotional $(\mathrm{RE})$ ); and psychological distress and wellbeing (mental health index $(\mathrm{MH})$ ), scored from 0 (worst) to 100 (best). ${ }^{35}$ Domain scores were normalised and z-transformed into PCS and MCS summary scores. PCS positively weights five domains (PF, RP, BP, GH and VT) and negatively weights the remaining three domains (SF, RE and $\mathrm{MH}$ ); MCS positively weights the four mental domains (VT, $\mathrm{SF}, \mathrm{RE}$ and $\mathrm{MH}$ ) and negatively weights the four physical domains (PF, RP, BP and GH). The normative value for the PCS or MCS summary score is 50 with a SD of $10 .^{1}$

SF-6D estimates health utilities from SF-36 data to derive a single index score that ranges from 0 (death) to 1 (full health). SF-6D was initially based on individual patient data using answers to 11 items from the SF-36 questionnaire. ${ }^{36}$ SF-6D has recently been calculated based on group data using mean changes in each of the eight domains. ${ }^{28} 29$ This SF-6D calculation

Table 1 Patient demographics and disease characteristics at baseline

\begin{tabular}{|c|c|c|c|}
\hline & $\begin{array}{l}\text { RA } \\
(N=528)\end{array}$ & $\begin{array}{l}\text { PsA } \\
(N=205)\end{array}$ & $\begin{array}{l}\text { Psoriasis } \\
(\mathrm{N}=583)\end{array}$ \\
\hline \multicolumn{4}{|l|}{ Sex, n (\%) } \\
\hline Men & $141(27)$ & $105(51)$ & $382(66)$ \\
\hline Women & $387(73)$ & $100(49)$ & $201(34)$ \\
\hline Age, mean years (SD) & $51.4(0.6)^{*}$ & $47.4(11.1)$ & $45.2(11.9)$ \\
\hline Range & $18-84$ & $18-76$ & $18-87$ \\
\hline \multicolumn{4}{|l|}{ Race/ethnicity, n (\%) } \\
\hline White & $463(88)$ & $186(91)$ & $528(91)$ \\
\hline Black/African-American & $6(1)$ & $5(2)$ & $8(1)$ \\
\hline Hispanic/Latino & $27(5)$ & $11(5)$ & $19(3)$ \\
\hline Other & $32(6)$ & $3(2)$ & $28(5)$ \\
\hline \multicolumn{4}{|l|}{ Disease duration, mean } \\
\hline RA & $9.0 \mathrm{mos}$ & - & - \\
\hline PsA & - & $9.1 \mathrm{yrs}$ & - \\
\hline Psoriasis & - & $19.0 \mathrm{yrs}$ & 20.5 yrs \\
\hline \multicolumn{4}{|l|}{ Previous therapies } \\
\hline n (\%) DMARD & $113(21)$ & $156(76)$ & - \\
\hline Psoriasis therapies & - & $147(72)$ & $516(89)$ \\
\hline \multicolumn{4}{|l|}{ Disease characteristics } \\
\hline $\begin{array}{l}\text { Tender joint count, } \\
\text { mean no (SD) }\end{array}$ & $25.0(14.5) \dagger$ & $21.3(14.3) \ddagger$ & - \\
\hline $\begin{array}{l}\text { Swollen joint count, } \\
\text { mean no (SD) }\end{array}$ & $17.3(10.2) \S$ & $15.6(10.6)^{* *}$ & - \\
\hline PASI score, $† \dagger$ mean (SD) & - & $10.4(10.7) \ddagger \ddagger$ & $19.1(8.5)$ \\
\hline $\begin{array}{l}\text { Psoriasis-affected BSA, } \\
\text { mean \% (SD) }\end{array}$ & - & $10.6(15.4)$ & $28.0(17.4)$ \\
\hline \multicolumn{4}{|l|}{ Patient-reported outcomes } \\
\hline HAQ,§§ mean score (SD) & $1.7(0.7)$ & $1.1(0.6)$ & - \\
\hline DLOI, ๆI mean score (SD) & - & - & $11.7(6.8)$ \\
\hline
\end{tabular}

*Data represent mean (standard error) for patients with RA.

†71 possible joints.

$\ddagger 78$ possible joints.

$\S 68$ possible joints.

**76 possible joints.

††PASI scores range from 0 (no psoriasis) to 72 (severe disease).

‡¥PASI scores were only collected from psoriasis patients with affected BSA $\geq 3 \%$ $(n=128)$.

$\S \S \mathrm{HAO}$ scores range from 0 to 3 .

IDLOl scores range from 0 (no effect on patient's life) to 30 (extremely large effect on patient's life).

BSA, body surface area; DLOI, dermatology life quality index; DMARD, diseasemodifying antirheumatic drug; $\mathrm{HAO}$, health assessment questionnaire; PASI, psoriasis area and severity index; PsA, psoriatic arthritis; RA, rheumatoid arthritis. has been validated in RA and other rheumatic diseases with a minimally important difference (MID) of $0.041 .^{29}$

The PCS and MCS component scores of SF-36 were initially assessed in each of the clinical trials and if the results of either were statistically significant, mean changes in domains were assessed for statistical significance without $p$ value corrections, as customary, and for improvements meeting or exceeding the minimum clinically important difference (MCID) of 5-10 points for domain scores and 2.5-5 points for PCS and MCS scores. ${ }^{1}$ These MCID values (which were established for RA patients) apply similarly to PsA and psoriasis. ${ }^{37} 38$ Similarly, MCID values have been estimated in psoriasis for PCS (0.51-3.91, best estimate at 2.5) and MCS (3.89-6.61), which are in the range of the defined MCID we utilised. ${ }^{39}$ SF-6D MID was calculated based on the derivation by Ara and Brazier; ${ }^{28} 29$ recent data also indicate that MID for RA and PsA are similar for the SF-6D. ${ }^{40}$

Baseline and treatment-associated improvements were quantified across all eight domains using spydergrams and health utility measure SF-6D. To generate the spydergrams, domain scores were plotted from 0 (worst) at the centre to 100 (best) at the outer edge. Demarcations along each axis/domain represent changes of 10 points, an estimated one to two times the MCID. ${ }^{30}$ Baseline and endpoint domain scores in each study were compared with age and gender-matched normative SF-36 data from the USA. ${ }^{41}$

\section{Results}

Data for these analyses were obtained from 528 patients with RA, 205 patients with PsA and 583 patients with psoriasis (table 1). The majority of patients in all trials were white, most patients with RA were women, and most patients with psoriasis were men. All patients in the PsA trial also had psoriasis.

In RA patients enrolled in COMET, baseline PCS scores were low, approaching 2 SD below normative values of 50; MCS scores were more than 0.5 SD less than norms (table 2). After 52 weeks of treatment, improvement in the PCS score was greater with the etanercept plus methotrexate combination therapy than with methotrexate alone $(p=0.0031)$. Improvements in MCS with both treatments were large, exceeded the MCID, and approached normative values.

Large reductions in domain scores were reported by RA patients at baseline and were largest in $\mathrm{RP}$ and $\mathrm{BP}$ (figure 1A,B). After 52 weeks of treatment, statistically significant $(p<0.0001)$ and clinically meaningful improvements ( $\geq$ MCID) across all domains were evident with both treatments. Greatest improvements were seen in both treatment groups in domains with the lowest scores at baseline: RP (improvements of $46.5 \mathrm{vs}$ 40.8 points in the etanercept plus methotrexate vs methotrexate arms), BP (37.2 vs 29.6 points) and RE (32.7 vs 25.9 points). Etanercept plus methotrexate therapy was associated with greater improvements in PF, BP and VT domains compared with methotrexate therapy alone (figure $1 \mathrm{C}$ ).

Mean SF-6D scores in patients with RA at baseline (0.529) were considerably lower than age and gender-matched norms (0.822). Clinically meaningful improvements ( $\geq$ MID) were observed in SF-6D scores in patients receiving etanercept plus methotrexate (mean score 0.658) and methotrexate alone (mean score 0.635). Improvements in SF-6D scores were significantly greater in patients receiving etanercept plus methotrexate compared with methotrexate alone $(p=0.05)$.

In patients with PsA enrolled in Study 160030, baseline PCS scores were low in all patients, approaching $1.5 \mathrm{SD}$ below the normative value of 50 (table 2). MCS scores approximated 
Table 2 Mean baseline and post-treatment SF-36 PCS and MCS scores and SF-6D scores across trials

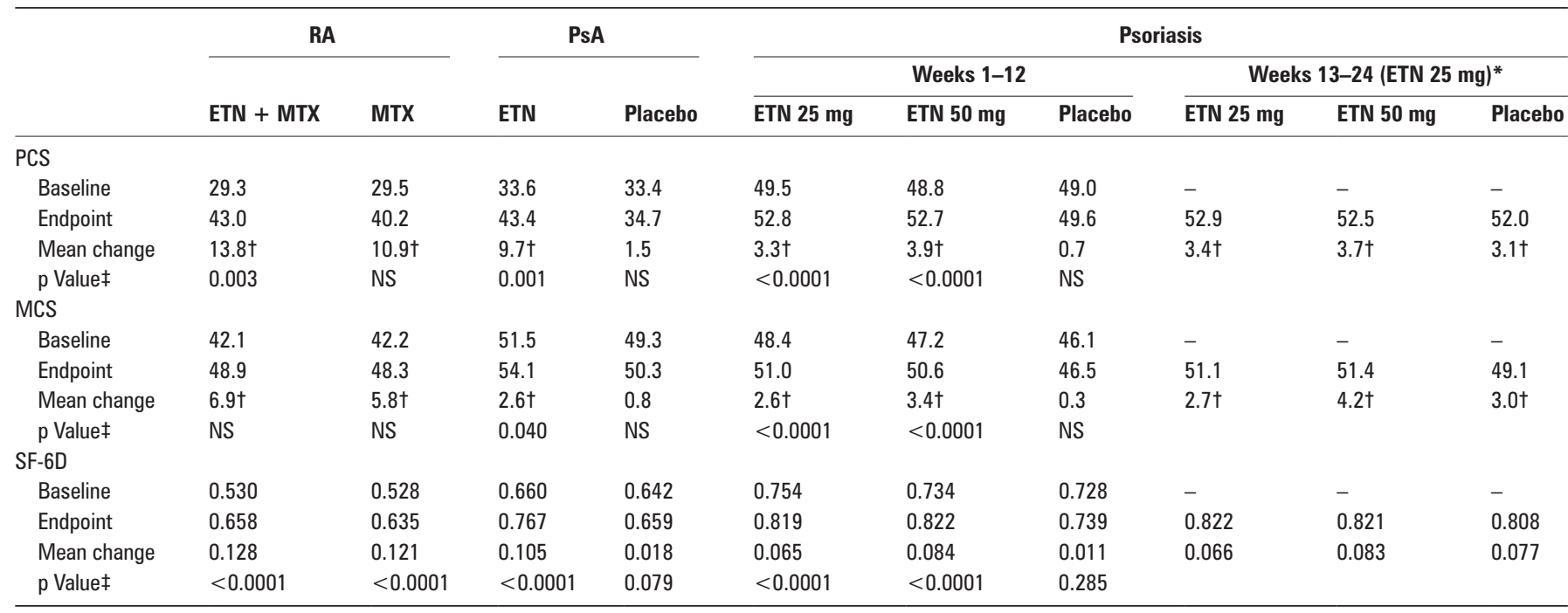

${ }^{*}$ All patients received etanercept $25 \mathrm{mg}$ twice a week during weeks 13-24, column headers represent original treatment assignment, p values are comparisons with week 12 values. tChanges were greater than or equal to the minimal clinically important difference (MCID).

$\ddagger p$ Value for change from baseline.

ETN, etanercept; MCS, mental component summary; MTX, methotrexate; NS, not significant; PCS, physical component summary; PsA, psoriatic arthritis; RA, rheumatoid arthritis;

SF-36, short form 36; SF-6D, health utility score based on mean scores across all eight domains of the SF-36.

normative values. After 24 weeks of treatment, patients receiving etanercept reported statistically significant and clinically meaningful improvements in both PCS (to within $0.5 \mathrm{SD}$ of norms) and MCS (exceeding normative values) scores from baseline. Significant improvements were not reported by patients receiving placebo.

Large reductions were reported in all domains of the SF-36 at baseline in patients with PsA (figure 2A,B); the most severely impacted domains were RP, BP and VT. After 24 weeks of treatment, statistically significant and clinically meaningful improvements in all domains were reported by patients receiving etanercept ( $<<0.0001$ for all domains except RE, $p=0.004)$; the greatest improvements were in the physical domains RP (25.8 points), BP (23.4 points) and PF (20.4 points). Patients receiving placebo reported statistically significant and clinically meaningful improvements in PF (4.2 points), BP (5.8 points), VT (4.5 points) and SF (5.6 points). Etanercept therapy was associated with greater improvements across all domains compared with placebo (figure 2C).

Mean SF-6D scores in patients with PsA (0.651) were considerably lower than age and gender-matched norms (0.848). After 24 weeks of treatment, clinically meaningful improvements in SF-6D scores were reported by patients receiving etanercept (mean score 0.767 ) but not placebo (mean score 0.659).

In patients with psoriasis enrolled in Study 160042, baseline PCS scores were high in all patients and approximated normative values of 50; MCS scores were within less than 0.5 SD of norms (table 2). After 12 weeks of treatment, statistically significant improvements in both PCS and MCS scores were observed in patients receiving etanercept at both doses $(p<0.0001)$ but not in patients receiving placebo. Despite high baseline values, treatment-associated improvements in PCS and MCS scores exceeded MCID and resulted in final scores that exceeded normative values. During weeks 13-24 of the study, when all patients received open-label etanercept at $25 \mathrm{mg}$ twice a week, patients who had received etanercept during weeks 1-12 maintained their improvements in PCS and MCS scores, even in the treatment arm in which the dosage was reduced from $50 \mathrm{mg}$ twice a week in the first 12 weeks to $25 \mathrm{mg}$ twice a week for the open-label phase of the trial. Patients who initially received placebo reported clinically meaningful improvements in both PCS and MCS after 12 weeks of receiving open-label etanercept.

Overall, patients with psoriasis reported lower reductions in physical and mental domains of SF-36 than patients with RA or PsA, and baseline SF-36 domain scores approximated normal values in most domains (figure $3 \mathrm{~A}-\mathrm{C}$ ). The lowest scores were in the $\mathrm{BP}, \mathrm{GH}, \mathrm{VT}$ and $\mathrm{MH}$ domains. Despite high values at baseline, after 12 weeks of treatment, improvements were reported in all domains and clinically meaningful improvements were reported in all domains except $\mathrm{GH}$ in patients receiving etanercept at either dose. In both active treatment groups, the largest mean changes were reported in BP (14.6 points and 16.5 points for etanercept $25 \mathrm{mg}$ twice a week and $50 \mathrm{mg}$ twice a week, respectively), SF (8.9 points and 13.8 points), RP (9.8 points and 13.1 points) and RE (10.5 points and 10.4 points) domains. No statistically significant or clinically meaningful changes were reported in patients receiving placebo. During the open-label phase of the trial, patients who had initially received etanercept at either dose maintained their improvements and patients who initially received placebo achieved clinically meaningful improvements in all domains but PF and GH (figure 3D-F).

The mean baseline SF-6D score was higher in patients with psoriasis (0.739) than in patients with RA or PsA, but was still less than age and gender-matched norms (0.854). Clinically meaningful improvements $(\geq \mathrm{MID})$ were observed in patients receiving active treatment but not in patients receiving placebo; in addition, during the open-label phase of the trial, improvements were also reported in patients initially treated with placebo (table 2).

\section{Discussion}

Our data confirm that HRQoL is much diminished in patients with PsA and RA compared with age and gender-matched norms. A very interesting observation from these data is that the baseline patterns of HRQoL reductions appear to be different in each disease, as illustrated by the spydergrams. Patients 
A. Methotrexate

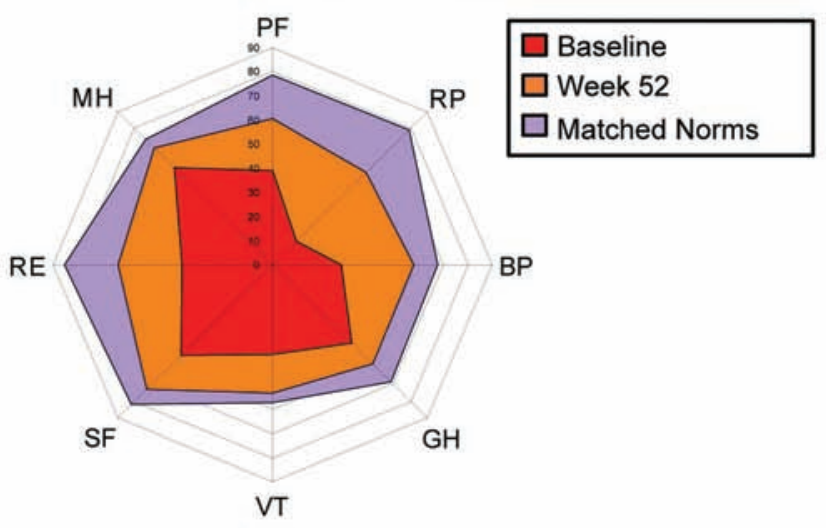

B. Etanercept + Methotrexate

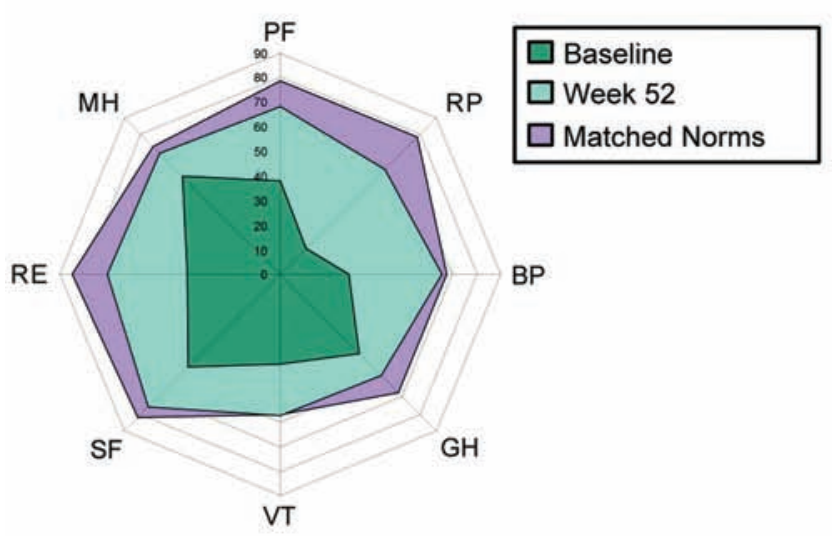

C. Methotrexate vs Etanercept + Methotrexate

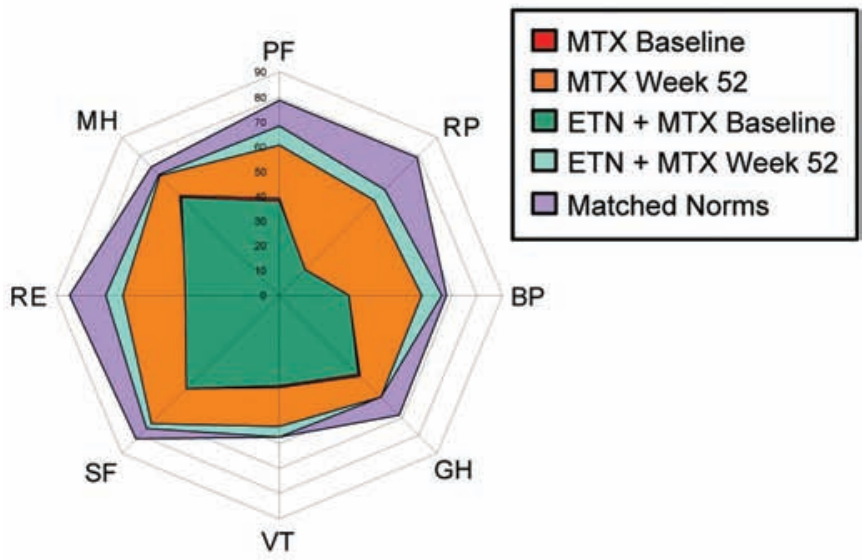

Figure 1 Short form 36 (SF-36) spydergrams for patients with rheumatoid arthritis. Mean SF-36 scores at baseline and week 52 and age and gender-matched norms are shown for patients receiving $(A)$ methotrexate or (B) etanercept plus methotrexate. (C) Mean SF-36 scores at baseline and week 52 for patients treated with methotrexate or etanercept plus methotrexate are compared. Mean SF-36 scores for age and gendermatched norms are also shown. BP, bodily pain; ETN, etanercept; $\mathrm{GH}$, general health; MH, mental health; MTX, methotrexate; PF, physical function; RE, role emotional; RP, role physical; SF, social functioning; VT, vitality.

with arthritis (either RA or PsA) reported an impact of disease on physical function (RP and PF domains), pain (BP) and fatigue (VT). These further affect emotional and social functioning

\section{A. Placebo}
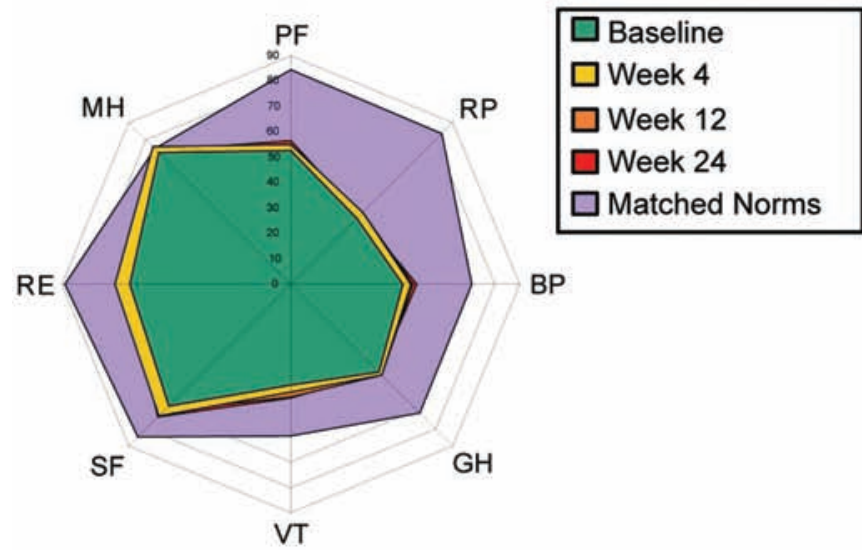

BP

\section{B. Etanercept}
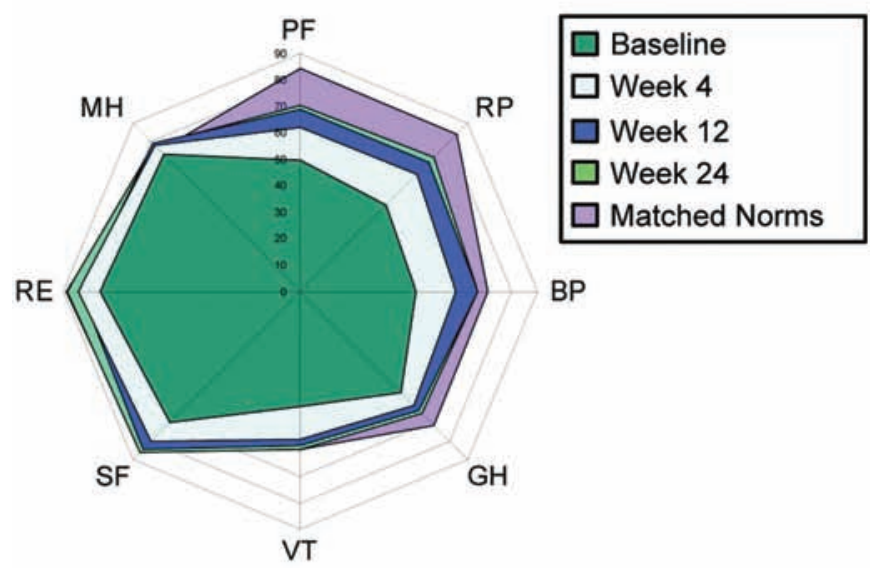

BP

\section{Placebo vs Etanercept}

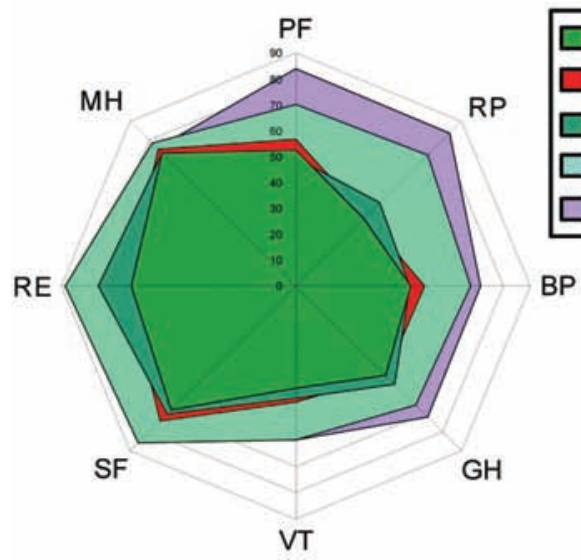

Figure 2 Short form 36 (SF-36) spydergrams for patients with psoriatic arthritis. Mean SF-36 scores at baseline and weeks 4, 12 and 24, and age and gender-matched norms are shown for patients receiving (A) placebo or (B) etanercept. (C) Mean SF-36 scores at baseline and week 24 for patients treated with placebo or etanercept are compared. Mean SF-36 scores for age and gender-matched norms are also shown. $\mathrm{BP}$, bodily pain; ETN, etanercept; $\mathrm{GH}$, general health; $\mathrm{MH}$, mental health; $\mathrm{PF}$, physical function; $\mathrm{PL}$, placebo; $\mathrm{RE}$, role emotional; $\mathrm{RP}$, role physical; SF, social functioning; VT, vitality.

(RE and SF domains) in RA. In contrast, psoriasis has a relatively greater impact on mental rather than physical domains, as patients with psoriasis report the effect of their disease on 


\section{A. Placebo (RCT) Week 12}

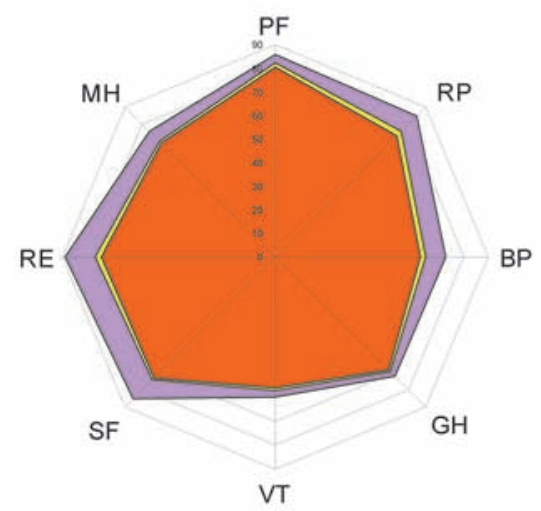

Baseline $\square$ Week $12 \quad \square$ Matched Norms

D. Placebo (RCT)/ Etanercept 25 mg BIW (OL)

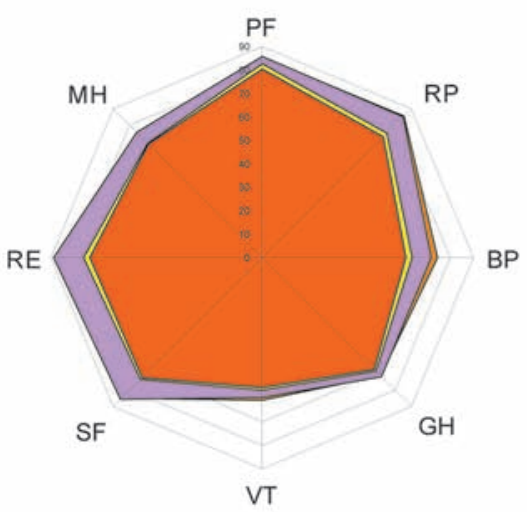

$\begin{array}{|ll|}\square \text { Baseline } & \square \text { Week } 12 \\ \square \text { Week 24 } & \square \text { Matched Norms }\end{array}$
B. Etanercept $25 \mathrm{mg}$ BIW (RCT) Week 12

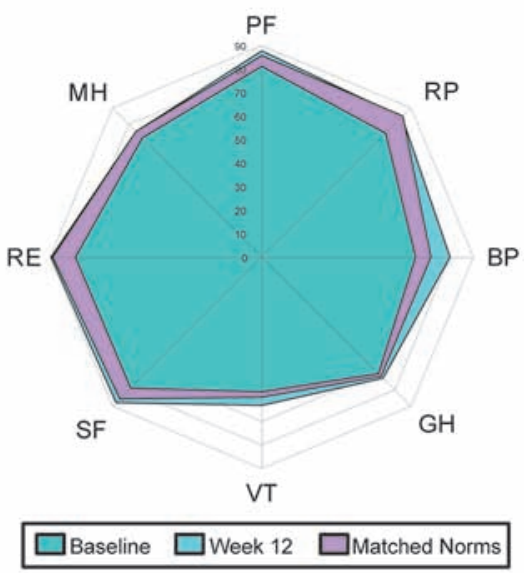

\section{E. Etanercept $25 \mathrm{mg}(\mathrm{RCT}) /$ Etanercept 25 mg BIW (OL) Week 24}

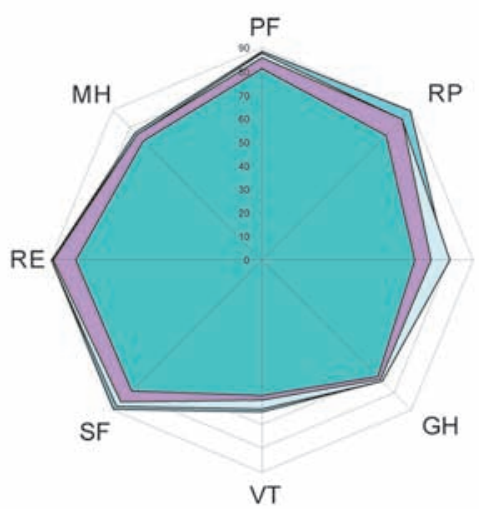

BP

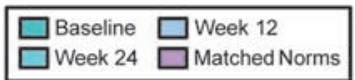

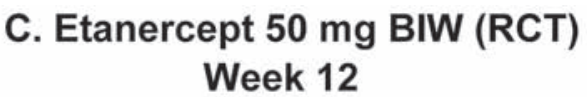

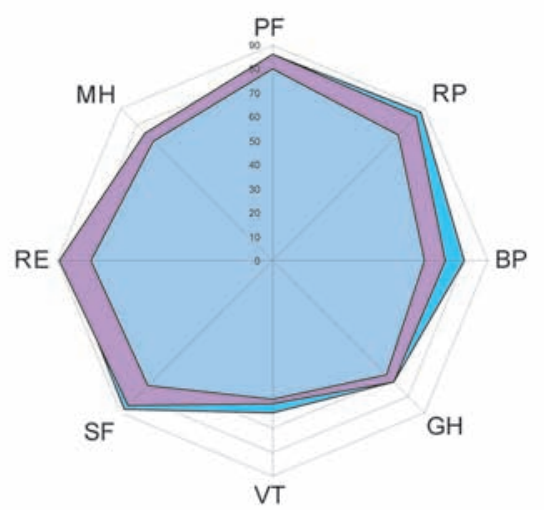

$\square$ Baseline $\square$ Week $12 \quad \square$ Matched Norms

\section{F. Etanercept $50 \mathrm{mg} \mathrm{BIW} \mathrm{(RCT)/}$ Etanercept $25 \mathrm{mg}$ BIW (OL) Week 24}
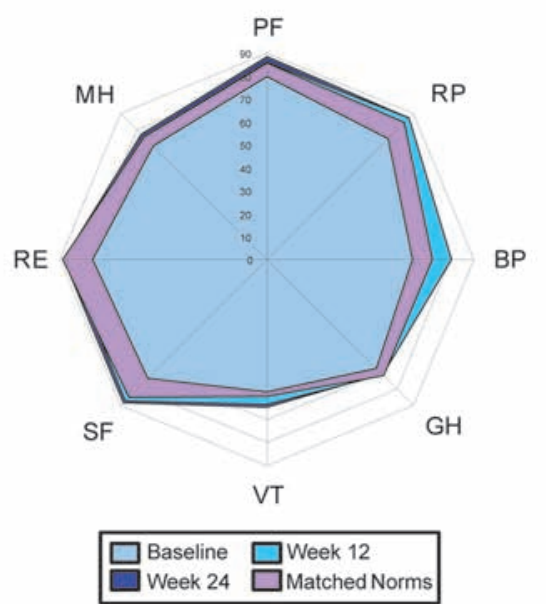

$$
\begin{array}{ll}
\mathrm{PF}=\text { Physical Function } & \mathrm{VT}=\text { Vitality } \\
\mathrm{RP}=\text { Role Physical } & \mathrm{SF}=\text { Social Functioning } \\
\mathrm{BP}=\text { Bodily Pain } & \mathrm{RE}=\text { Role Emotional } \\
\mathrm{GH}=\text { General Health } & \mathrm{MH}=\text { Mental Health Index }
\end{array}
$$

Figure 3 Short form 36 (SF-36) spydergrams for patients with psoriasis. Mean SF-36 scores at baseline and week 12 of the randomised controlled trial (RCT) portion of the clinical trial and age and gender-matched norms are shown for patients receiving $(A)$ placebo, $(B)$ etanercept $25 \mathrm{mg}$ twice a week (BIW), or (C) etanercept 50 mg twice a week. Mean SF-36 scores at baseline and weeks 12 and 24 of the open-label (OL) portion of the trial (when all patients received etanercept $25 \mathrm{mg}$ twice a week) are shown for patients who had received (D) placebo, (E) etanercept $25 \mathrm{mg}$ twice a week, or (F) etanercept 50 mg twice a week during the RCT portion of the trial. Mean SF-36 scores for age and gender-matched norms are also shown.

social functioning (RE and SF), and to a lesser degree on physical function (RP) and pain (BP) domains. This is consistent with data obtained from large clinical trials in psoriasis. This suggests that the impact of physical wellbeing on mental health might well depend on the nature of the physical impairment (eg, skin versus joint), as skin disease may have a disproportionally large effect on mental function and ensuing quality of life. Another explanation for the apparently small diminution in physical domains in psoriasis is that the SF-36 is not a particularly sensitive measure of skin disease in psoriasis-although changes in the physical domains correlate with changes in objective measures of disease, relatively large changes in skin disease are required in order to register a change in the SF-36 physical domain scores in psoriasis. ${ }^{19}{ }^{42}$ In addition, comparison of all diseases by spydergrams reveals characteristic 'notches' in domains for a given disease. These domain deficits unique to a particular disease should focus future research on the variables associated with these changes and how these might be more effectively addressed. A limitation in comparing HRQoL across diseases includes the duration of disease in the populations in these analyses; the mean duration of disease at baseline was 9 months, 9 years and approximately 20 years for patients 
with RA, PsA and psoriasis, respectively, with broad ranges. Clearly, this variability may have a significant impact on perceptions of disease and therefore HRQoL reported before and after treatment.

Because the age and gender-matched norms were very similar to one another in all three diseases, we were able to compare all baseline SF-36 domain scores in one spydergram (figure 4). The magnitude of reduction in disease compared with age and gender-matched normative values in domain scores was greatest in RA followed by PsA, and of overall lesser magnitude in psoriasis. While the physical health domain scores were much lower in PsA than in psoriasis, mental health domain scores were very similar in the two diseases except for VT, which was substantially lower in PsA. This is consistent with the theory that much of the negative mental impact in PsA is caused by skin disease. ${ }^{43}$ Given that reports in the literature support the connection between educational status and negative mental impact of disease in arthritis, this might have implications for educational interventions to prevent the same negative mental impacts in psoriasis.

While it is easy to understand the diminished social and emotional functioning in arthritis (RA and PsA) caused by physical limitation and pain, it may be difficult immediately to rationalise why patients with psoriasis have diminished physical health. However, pain and itching from skin disease are known to result in inability to function in the workplace, use one's hands (as palm involvement is common in psoriasis), and can result in sleep disturbances that characterise psoriasis and result in inability to participate in various physical activities related to work or leisure. In addition, it is known that psychological comorbidities such as depression and anxiety are associated with psoriasis. Our data suggest that the physical and mental domains of HRQoL are connected. Diminished mental health in psoriasis may result from concern over the appearance of the psoriatic skin, leading to anxiety, a sense of stigmatisation and embarrassment, reduction in participation in work and leisure activities and diminishment of a patient's psychological wellbeing. The mental and physical domains in psoriasis might also be uniquely connected by bodily pain. BP is consistently found to be among the most affected physical domains in psoriasis, which is likely to be due to skin pain from psoriatic plaques, as objective measures of skin disease tend to correlate well with the BP subscale. ${ }^{4}$ Pain and itching of the skin can cause both emotional and physical distress. Physical health may be affected by the itching and burning sensation of the skin and by joint pain in those with concomitant arthritis. ${ }^{912}$ Interestingly, depression also impacts $\mathrm{BP}$ in psoriasis. ${ }^{21}$ In addition, skin pain (and itching) probably contributes to sleep disturbance, which is an important component of mental HRQoL in psoriasis. Sleep disturbance could directly contribute to fatigue and social function. BP has often been seen to be prone to greatest improvements of all SF-36 domains following therapy in psoriasis patients, and this is consistent with our data. ${ }^{20}$ It is of note that this improvement has been seen with a number of therapies, including anti-TNF therapies, ustekinumab (which targets interleukins 12 and 23) ${ }^{42}$ and efalizumab (which targets CD11a). ${ }^{44}$ It has also recently been shown that depression impacts heavily on the BP domain in psoriasis, ${ }^{21}$ and this may be more uniquely associated with psoriasis than with RA or PsA.

Following treatment with etanercept, the largest improvements were seen in physical domains as well as RE in RA patients. In patients with psoriasis, despite potential ceiling effects, treatment-associated changes could still be demonstrated. Our findings were similar to those of Revicki et a ${ }^{12}$ but

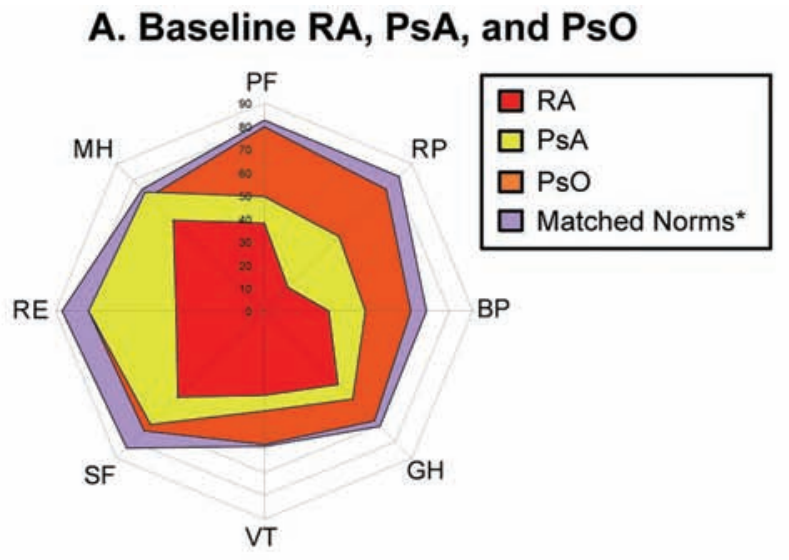

B. Endpoint Values for RA vs PsA vs PsO

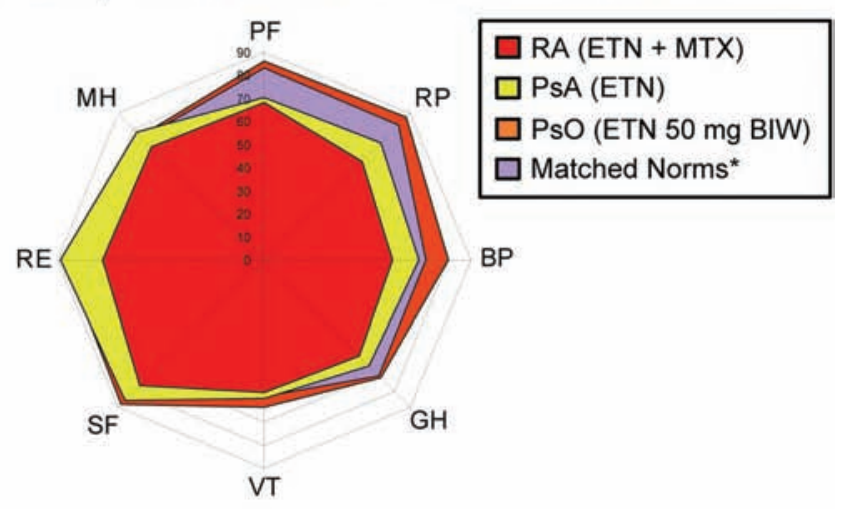

C. Matched Norms for RA, PsA, and PsO at Baseline

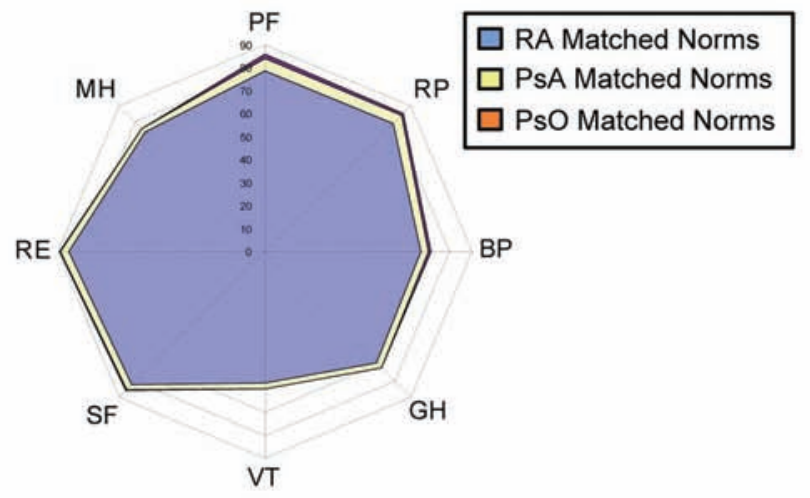

*Age- and gender-matched norms for etanercept-treated patients averaged across all indications

Figure 4 Comparison of health-related quality of life (HROoL) across indications. (A) Mean short form 36 (SF-36) scores for patients with rheumatoid arthritis (RA), psoriatic arthritis (PsA), or psoriasis (PsO) at baseline and average age and gender-matched norms for all indications are shown. (B) Mean SF-36 values at endpoint are shown for patients with RA (etanercept (ETN) plus methotrexate (MTX)-treated patients at week 52), PsA (etanercept-treated patients at week 24), and psoriasis (etanercept $50 \mathrm{mg}$ twice a week (BIW)-treated patients at week 12) with average age and gender-matched norms for all indications. (C) Mean SF-36 scores at baseline for age and gender-matched norms are shown.

differ from some earlier studies in which the control population was not appropriately matched to the study group. For some domains (eg, BP), post-treatment values actually exceeded those of the age-matched controls, suggesting that some aspects of 
chronic skin disease/pain might extinguish other pain stimuli to some degree so that when treated, patients actually feel less pain than norms.

A unique aspect of the SF-36 is that lower domain scores represent worse disease. This paper demonstrates that these lower domain scores are often associated with the largest treatmentassociated changes towards improvement. The use of spydergrams made this evident, as treatment was associated with loss of 'notching' and more even 'rounding' of the spydergram patterns for both RA and PsA (compare figure 4A,B). In contrast, improvements are less easily demonstrated using the health assessment questionnaire disability index that also assesses physical function probably because higher scores indicate worse outcome. In addition, SF-36 data are normalised; this scoring method inherently leads to fewer floor (or ceiling) effects, as is evident in both RA and PsA datasets.

SF-6D scores are a means for quantifying changes illustrated in the spydergrams. As in patients with RA and PsA, SF-36 is a useful tool for assessing HRQoL in patients with psoriasis. Questions in the SF-36 may be less sensitive to the impact of skin disease in the absence of arthritis; however, statistically significant and clinically meaningful treatment-associated improvements were demonstrated in psoriasis patients. Furthermore, our results illustrated less potential for 'ceiling effects' with this instrument, as reflected in improvements that exceeded normative values even with high domain scores at baseline as in psoriasis.

Several domains from SF-36, a generic HRQoL assessment tool, have been shown to correspond with items from diseasespecific tools, such as the dermatology life quality index for psoriasis $^{26} 3839$ and the health assessment questionnaire for $\mathrm{RA}^{4546}$ and PsA. ${ }^{37}$ In both research and clinical settings, visual representation of SF-36 data in spydergram format would be most useful for measuring improvements or changes in response to treatment in a cohort of patients. In clinical practice, spydergrams would also be useful for routine monitoring of the mental domains of HRQoL. In addition to normal physical examinations of joints and/or skin, patient-reported information from SF-36 would complement physical findings to provide the clinician with a more comprehensive evaluation of each patient.

\section{Conclusions}

In this study we directly compared HRQoL in patients with RA, PsA and psoriasis and showed that each disease had a unique profile among physical and mental health domains. There were differences in the magnitude of change between the three diseases, but not in the ability of RA, PsA and psoriasis patients to achieve HRQoL improvements. Similar to other studies using anti-TNF agents, we showed that improvements are achieved in response to therapy in both physical and mental health components of the SF-36 in all three diseases.

Acknowledgments The authors would like to thank Julia R. Gage, PhD, whose work was funded by Amgen Inc, for assistance with writing the manuscript.

Funding These analyses were funded by Immunex Corporation, a wholly owned subsidiary of Amgen Inc, and by Wyeth, which was acquired by Pfizer Inc in October 2009.

Competing interests ViS has been a consultant to Abbott Immunology, Alder Biopharmaceuticals, Amgen, Biogenldec, Bristol-Myers Squibb, CBio, CanFite, Centocor, Chelsea Therapeutics, Emergent Biosolutions, Genentech, GlaxoSmithKline, Idera, Incyte, Iroko, Lexicon Genetics, Nuon Therapeutics, Pfizer, Regeneron, Rigel, Roche, Sanofi-Aventis, Schering Plough and UCB. VeS and DF have no conflicts to declare. ASK is an employee and shareholder of Pfizer Inc. GP, YS and DJZ are employees and shareholders of Amgen Inc. BW is a consultant for Amgen Inc.
Ethics approval Approval was obtained from the institutional review boards at all study sites.

Provenance and peer review Not commissioned; externally peer reviewed.

\section{REFERENCES}

1. Strand V, Singh JA. Newer biological agents in rheumatoid arthritis: impact on health-related quality of life and productivity. Drugs 2010;70:121-45.

2. Singh JA, Strand V. Spondyloarthritis is associated with poor function and physical health-related quality of life. J Rheumatol 2009;36:1012-20.

3. Sokoll KB, Helliwell PS. Comparison of disability and quality of life in rheumatoid and psoriatic arthritis. J Rheumatol 2001;28:1842-6.

4. Husted JA, Gladman DD, Farewell VT, et al. Health-related quality of life of patients with psoriatic arthritis: a comparison with patients with rheumatoid arthritis. Arthritis Rheum 2001;45:151-8.

5. Borman P, Toy GG, Babaoglu S, et al. A comparative evaluation of quality of life and life satisfaction in patients with psoriatic and rheumatoid arthritis. Clin Rheumatol 2007;26:330-4.

6. de Korte J, Sprangers MA, Mombers FM, et al. Quality of life in patients with psoriasis: a systematic literature review. J Invest Dermatol Symp Proc 2004;9:140-7.

7. Kimball AB, Jacobson C, Weiss $S$, et al. The psychosocial burden of psoriasis. Am J Clin Dermatol 2005;6:383-92.

8. Fortune DG, Main CJ, O'Sullivan TM, et al. Quality of life in patients with psoriasis: the contribution of clinical variables and psoriasis-specific stress. Br J Dermatol 1997; 137:755-60.

9. Rapp SR, Feldman SR, Exum ML, et al. Psoriasis causes as much disability as other major medical diseases. J Am Acad Dermatol 1999;41:401-7.

10. Krueger G, Koo J, Lebwohl M, et al. The impact of psoriasis on quality of life: results of a 1998 National Psoriasis Foundation patient-membership survey. Arch Dermatol 2001;137:280-4

11. Prinz JC, Fitzgerald O, Boggs Rl, et al. Combination of skin, joint and quality of life outcomes with etanercept in psoriasis and psoriatic arthritis in the PRESTA trial. J Eur Acad Dermatol Venereol 2011;25:559-64.

12. Revicki DA, Menter A, Feldman S, et al. Adalimumab improves health-related quality of life in patients with moderate to severe plaque psoriasis compared with the United States general population norms: results from a randomized, controlled phase III study. Health Qual Life Outcomes 2008;6:75.

13. Kavanaugh A, Antoni C, Krueger GG, et al. Infliximab improves health related quality of life and physical function in patients with psoriatic arthritis. Ann Rheum Dis 2006;65:471-7.

14. Krueger GG, Langley RG, Finlay AY, et al. Patient-reported outcomes of psoriasis improvement with etanercept therapy: results of a randomized phase III trial. Br J Dermato/ 2005;153:1192-9.

15. Han C, Smolen JS, Kavanaugh A, et al. The impact of infliximab treatment on quality of life in patients with inflammatory rheumatic diseases. Arthritis Res Ther 2007;9:R103.

16. Maini RN, Breedveld FC, Kalden JR, et al. Sustained improvement over two years in physical function, structural damage, and signs and symptoms among patients with rheumatoid arthritis treated with infliximab and methotrexate. Arthritis Rheum 2004;50:1051-65.

17. Papp KA, Tyring S, Lahfa M, et al. A global phase III randomized controlled trial of etanercept in psoriasis: safety, efficacy, and effect of dose reduction. Br J Dermatol 2005;152:1304-12.

18. Sterry W, Ortonne JP, Kirkham B, et al. Comparison of two etanercept regimens for treatment of psoriasis and psoriatic arthritis: PRESTA randomised double blind multicentre trial. BMJ 2010;340:c147.

19. Revicki DA, Willian MK, Menter A, et al. Relationship between clinical response to therapy and health-related quality of life outcomes in patients with moderate to severe plaque psoriasis. Dermatology (Basel) 2008;216:260-70.

20. Reich K, Nestle F0, Papp K, et al. Improvement in quality of life with infliximab induction and maintenance therapy in patients with moderate-to-severe psoriasis: a randomized controlled trial. Br J Dermatol 2006;154:1161-8.

21. Feldman SR, Gottlieb $A B$, Bala $M$, et al. Infliximab improves health-related quality of life in the presence of comorbidities among patients with moderate-to-severe psoriasis. Br J Dermatol 2008;159:704-10.

22. Saad AA, Ashcroft DM, Watson KD, et al. Improvements in quality of life and functional status in patients with psoriatic arthritis receiving anti-tumor necrosis factor therapies. Arthritis Care Res (Hoboken) 2010;62:345-53.

23. Linde L, Sørensen J, Ostergaard M, et al. Health-related quality of life: validity, reliability, and responsiveness of SF-36, 15D, EQ-5D [corrected] RAOoL, and HAO in patients with rheumatoid arthritis. J Rheumatol 2008;35:1528-37.

24. Husted JA, Gladman DD, Farewell VT, et al. Validating the SF-36 health survey questionnaire in patients with psoriatic arthritis. J Rheumatol 1997; 24:511-7.

25. Leung YY, Ho KW, Zhu TY, et al. Testing scaling assumptions, reliability and validity of medical outcomes study short-form 36 health survey in psoriatic arthritis. Rheumatology (Oxford) 2010;49:1495-501. 
26. Nichol MB, Margolies JE, Lippa E, et al. The application of multiple quality-of-life instruments in individuals with mild-to-moderate psoriasis. Pharmacoeconomics 1996:10:644-53.

27. Bronsard V, Paul C, Prey S, et al. What are the best outcome measures for assessing quality of life in plaque type psoriasis? A systematic review of the literature. J Eur Acad Dermatol Venereol 2010;24 (Suppl 2):17-22.

28. Ara R, Brazier J. Deriving an algorithm to convert the eight mean SF-36 dimension scores into a mean E0-5D preference-based score from published studies (where patient level data are not available). Value Health 2008;11:1131-43.

29. Ara R, Brazier J. Predicting the short form-6D preference-based index using the eight mean short form-36 health dimension scores: estimating preference-based healthrelated utilities when patient level data are not available. Value Health 2009;12:346-53.

30. Strand V, Crawford B, Singh J, et al. Use of "spydergrams" to present and interpret SF-36 health-related quality of life data across rheumatic diseases. Ann Rheum Dis 2009;68:1800-4.

31. Emery P, Breedveld FC, Hall S, et al. Comparison of methotrexate monotherapy with a combination of methotrexate and etanercept in active, early, moderate to severe rheumatoid arthritis (COMET): a randomised, double-blind, parallel treatment trial. Lancet 2008;372:375-82.

32. Kekow J, Moots RJ, Emery P, et al. Patient-reported outcomes improve with etanercept plus methotrexate in active early rheumatoid arthritis and the improvement is strongly associated with remission: the COMET trial. Ann Rheum Dis 2010;69:222-5.

33. Kekow J, Moots $\mathrm{R}$, Khandker $\mathrm{R}$, et al. Improvements in patient-reported outcomes, symptoms of depression and anxiety, and their association with clinical remission among patients with moderate-to-severe active early rheumatoid arthritis. Rheumatology (Oxford) 2011;50:401-9.

34. Mease PJ, Kivitz AJ, Burch FX, et al. Etanercept treatment of psoriatic arthritis: safety, efficacy, and effect on disease progression. Arthritis Rheum 2004;50:2264-72.

35. Ware JE, Jr, Kosinski M, Dewey JE. How to Score Version 2 of the SF-36 Health Survey. Lincoln, Rl: QualityMetric Inc, 2000.

36. Brazier J, Roberts J, Deverill M. The estimation of a preference-based measure of health from the SF-36. J Health Econ 2002;21:271-92.
37. Strand V Vessey A, Hu A, et al. Improved health-related quality of life (HROOL) with apremilast (APR) treatment in psoriatic arthritis (PsA): results from a phase 2 randomized controlled study (Abstract 1940). Arthritis Rheum 2010;62:S811.

38. Strand V, Hu A, Day R, et al. Improved quality of life with apremilast (APR) in the treatment of psoriasis: results from a phase Ilb randomized controlled study (Abstract P3337). J Am Acad Dermatol 2011;64:AB154.

39. Shikiar R, Willian MK, Okun MM, et al. The validity and responsiveness of three quality of life measures in the assessment of psoriasis patients: results of a phase II study. Health Qual Life Outcomes 2006;4:71.

40. Kvamme MK, Kristiansen IS, Lie E, et al. Identification of cutpoints for acceptable health status and important improvement in patient-reported outcomes, in rheumatoid arthritis, psoriatic arthritis, and ankylosing spondylitis. J Rheumatol 2010;37:26-31.

41. Ware JE, Jr. User's Manual for the SF-36v2 ${ }^{\text {TM }}$ Health Survey - Second Edition. Lincoln, Rl: QualityMetric Inc, 2000

42. Lebwohl M, Papp K, Han C, et al. Ustekinumab improves health-related quality of life in patients with moderate-to-severe psoriasis: results from the PHOENIX 1 trial. Br J Dermatol 2010;162:137-46.

43. Salaffi F, Carotti M, Gasparini S, et al. The health-related quality of life in rheumatoid arthritis, ankylosing spondylitis, and psoriatic arthritis: a comparison with a selected sample of healthy people. Health Qual Life Outcomes 2009;7:25.

44. Ortonne JP, Shear N, Shumack S, et al. Impact of efalizumab on patient-reported outcomes in high-need psoriasis patients: results of the international, randomized, placebo-controlled phase III Clinical Experience Acquired with Raptiva (CLEAR) trial [NCT00256139]. BMC Dermatol 2005;5:13

45. Birrell FN, Hassell $A B$, Jones PW, et al. How does the short form 36 health questionnaire (SF-36) in rheumatoid arthritis (RA) relate to RA outcome measures and SF-36 population values? A cross-sectional study. Clin Rheumatol 2000;19:195-9.

46. Tuttleman M, Pillemer SR, Tilley BC, et al. A cross sectional assessment of health status instruments in patients with rheumatoid arthritis participating in a clinical trial. Minocycline in Rheumatoid Arthritis Trial Group. J Rheumatol 1997:24:1910-5 